\title{
Be My Friend! Fostering Parasocial Relationships with Social Media Influencers: Findings from PLS-SEM and fsQCA
}

\section{Abstract \\ Purpose}

The emergence of social media has brought the influencer marketing landscape to an unprecedented level, where many ordinary people are turning into social media influencers. The study aims to construct and validate a model to yield strategic insights on the relevance of content curation, influencer-fans interaction, and parasocial relationships development in fostering favorable endorsement outcomes (i.e., purchase intention).

\section{Design/methodology/approach}

The present study analyzes data from a survey of 411 consumers using partial least squaresstructural equation modelling (PLS-SEM) and fuzzy set qualitative comparative analysis (fsQCA) to understand the net and combined effects of content attributes, interaction strategies, and parasocial relationships on purchase intention.

\section{Findings}

PLS-SEM results reveal that content attributes (i.e., prestige and expertise) and interaction strategies (i.e., interactivity and self-disclosure) positively influence parasocial relationships, and in turn, lead to high purchase intention. Findings from fsQCA indicate six solutions with different combinations of content attributes, interaction strategies, and parasocial relationships that sufficiently explain high purchase intention.

\section{Originality}

The present study demonstrates the roles of content attributes and interaction strategies in engendering parasocial relationships and the endorsement outcome (i.e., purchase intent) from both linear and non-linear (complexity) perspectives.

Keywords: Social media influencers, Influencer marketing, Parasocial relationships, Interactivity, Self-disclosure, Content attributes 


\section{Introduction}

Brands are increasingly turning to the marketing of products and services through endorsements and product mentions by individuals who have a mass social following (Aw and Chuah, 2021). In the past, the arena of influencer marketing is primarily limited to traditional celebrities, but the rapid growth of social media has empowered ordinary consumers to accumulate and reach out to the mass audience, typically by publicly consuming products and disseminating word-of-mouth (Hew et al., 2018), thereby bring forth to the emergence of social media influencers. In the digital age, social media influencers have become the darlings of brand marketers, and they are often deemed more effective than traditional celebrities as marketing message propagators (Jin et al., 2019). For instance, available evidence reveals that $70 \%$ of teenage YouTube subscribers prefer to take purchase recommendations from their favorite influencers compared to traditional celebrities (Influencer Marketing Hub, 2020). Correspondingly, $90 \%$ of surveyed organizations believe social media influencer marketing to be effective and many of them are dedicating budget for it in 2021 (Influencer Marketing Hub, 2020). The value of the influencer marketing industry is expected to witness a soar from $\$ 8$ billion in 2019 to \$15 billion by 2022 (Influencer Marketing Hub, 2020).

Correspondingly, brands are increasingly leveraging influencer marketing to disseminate product information, given that social media influencers are seen as authentic and credible market mavens. In the digital age, consumers are empowered in a way that their information source is no longer limited to brand-generated content. Quite the contrary, they even deem brand-generated content to be skeptical, which explained the suboptimal return generated by brands from their digital marketing expenditure (Kapitan and Silvera, 2016). As advocated by authors of recent studies (Aw and Chuah, 2021; Lou, 2021), the appeal of influencers among consumers and their perceived authenticity can be explained through the prism of parasocial relationships, which is known as "the one-sided relationships that individuals form with mediated personas” (Aw and Chuah, 2021, p. 147). To explain, the emergence of social media has narrowed the distance between influencers and their fans by offering a platform for direct two-way interactions, including like, follow, comment, as well as glimpses into influencers' everyday lives (Labrecque, 2014; Yuan and Lee, 2021). As a result of these repeated interactions, consumers tend to develop intensified illusionary intimacy as if they know the influencers in person (Breves et al., 2021).

Influencers develop and maintain meaningful relationships with consumers, and they have been deemed an important source of meaning in which symbolism is appropriated for 
self-concept construction (Escalas and Bettman, 2017). According to Moraes et al. (2019), commonly, influencers create and deliver meaning through product endorsement, and the influencer-consumers relationships determine how influencers' image and endorsement are interpreted, thereby outlining the importance of influencer-consumers relationships in the influencer marketing realm. Past studies in the influencer marketing literature have established the power of parasocial relationships in driving both positive brand-related (e.g., purchase intention) and influencer-related (e.g., source credibility) implications (Aw and Chuah, 2021; Breves et al., 2021; Chung and Cho, 2017; Reinikainen et al., 2020). However, existing influencer literature has devoted little attention to understanding the mechanism in fostering parasocial relationships. As explicated by prior studies (Yuan and Lou, 2020), several important questions remained unanswered: What are the drivers reinforcing the parasocial relationships between influencers and consumers? How do parasocial relationships determine consumption-related behaviors?

Against this backdrop, we set forth to address these questions by tapping into the role of content attributes and interaction strategies as the means to cultivate parasocial relationships and subsequent downstream consumption outcomes (i.e., purchase intent). Social media influencers are pivots that bridge the conversation between brands and consumers, whereby their content offers a ground to foster influencer-fans interactions and communal spirit (Martínez-López et al., 2020; Rosenthal and Brito, 2017). Apart from the extensively established application of the source effect model to parasocial relationships, emerging evidence suggests that social media content is an effective self-promotional tool for brands and social media influencers to develop parasocial relationships (Aw and Chuah, 2021; Feng et al., 2020; Labrecque, 2014). Therefore, it is imperative to adopt this new perspective to untangle the underlying mechanism that expounds consumer-related outcomes to social media influencer marketing. On top of that, we seek to understand the distinctive interaction strategies employed by social media influencers for relationship-building, namely interactivity and selfdisclosure. Authors of previous studies delineated that interactivity (i.e., the extent to which social media influencers participate in two-way communications with followers) and selfdisclosure (i.e., the extent to which social media influencers reveal their personal ideas and feelings to others) as two unique features distinguishing social media influencers and traditional celebrities that worth further examination particularly concerning influencer-fans relationships (Feng et al., 2020; Jun and Yi, 2020; Lou, 2021), thus motivated the present study. 
Notably, in the present study, while acknowledging the value of the traditional regression approach, we seek to stretch our understanding beyond the "net effects" of causal conditions mentioned above by uncovering their possible combination patterns in leading to a specific outcome. The existing literature on influencer endorsement primarily relied on the variance-based approach with symmetric and linear assumptions and believed identification of a single best factor as the optimal solution for the endorsement-related outcomes of interest. However, as noted by emerging studies (Pappas and Woodside, 2021), such an approach does not acknowledge the complex and non-linear consumer decision-making processes in reality. In addressing this research lacuna, we rest on the tenet of complexity theory and argue that the effects of content attributes, interaction strategies, and parasocial relationships on the endorsement outcome (i.e., purchase intent) are not "all or nothing” as presumed by past research. This is in recognition of the principle of equifinality and complexity in real-life phenomena where relationships among variables are often non-linear and subjected to interactions with other variables (Pappas and Woodside, 2021). In addition, variables can be configured in different combinations in explaining the same outcome of interest (Liu et al., 2017).

To address the aforementioned research gaps, our paper is organized as follows: After presenting our conceptual model in more detail, we discuss the methodology employed and provide empirical evidence supporting the proposed model and hypotheses. Lastly, we discuss our key findings and their implications for research and practice before offering suggestions for future research directions.

\section{Literature review}

\subsection{Social media influencers}

Social media bestows ordinary people with the power of self-branding, defined by Khamis et al. (2017) as "developing a distinctive public image for commercial gain and/or cultural capital” (p. 191). By posting distinctive stories and/or content, people enjoy the opportunity of developing a fan base and gaining online fame, resulting in the birth of social media influencers. Social media influencers may outperform traditional celebrities in terms of endorsement due to their nature of communications and interactions with consumers, of which they frequently share their personal life and engage in reciprocal interactions, which in turn make them more relatable and less distant (Breves et al., 2021). As a result, recommendations from social media 
influencers serve as effective social proofs to the endorsing brand's prospective consumers. In addition, social media influencers' commercial posts are often woven into their daily narratives, thereby curating genuine endorsement content that consumers enjoy (Kim et al., 2021).

In order to understand how influencer marketing works, authors of existing influencer literature, either embedded in social media influencers or traditional celebrities contexts, have taken the perspective of the source effect model and examined the role of influencers' personal attributes in influencing endorsement outcomes. Among the extensively established influencer attribute factors include attractiveness, credibility, and expertise (Chung and Cho, 2017; Schimmelpfennig and Hunt, 2020; Sokolova and Kefi, 2020; Torres et al., 2019; Yuan and Lou, 2020), and these attributes have been evidenced to evoke positive consumer perception and behavioral intention. Later, authors of extant studies have started to explore the unique traits of social media influencers such as the number of followers due to their massive presence on social media (Arora et al., 2021; De Veirman et al., 2017). In this emerging line of research, inconclusive results have been derived where some studies suggest positive impacts of a high number of followers on consumer perception and behavior, but others find insignificant or negative impacts (Aw and Chuah, 2021; Boerman, 2020; De Veirman et al., 2017). Table A1 presented in the appendix outlined the recent studies in influencer marketing.

Based on the literature review conducted, it can be concluded that there is scant research to date that has provided an overarching psychological mechanism of influence founded on the effectiveness of influencer marketing. In particular, the existing studies have devoted much effort to identify the influencers' characteristics such as attractiveness and credibility that promote desired endorsement outcomes (Chung and Cho, 2017; Sokolova and Kefi, 2020; Torres et al., 2019). This gap in the literature leads to a limited understanding of how social media influencers and their partnered brands can practically manage their self-presentation on social media, given that the social media content presentation and social media interactions with consumers are the keys to the success of an influencer endorsement, thus this area requires further exploration (Aw and Chuah, 2021; Liu et al., 2020). As outlined in prior research, understanding of the implications of interactivity and self-disclosure is under-developed whereby researchers need to seek not only whether these factors impact endorsement effectiveness but also identify the mechanism behind (Leile \& Baptista, 2021; Liu et al., 2020). Further, the influencer-consumers attachment has been heralded as the next frontier in the influencer marketing literature (Moraes et al., 2019) but surprisingly the understanding towards fostering relationships between consumers and influencers remains murky. For instance, 
although past research has identified social media interactions and influencer personal characteristics as antecedents to parasocial relationships (Aw and Labrecque, 2020; Chung and Cho, 2017; Sokolova and Kefi, 2020), they did not explicitly offer insights into the specific content and interaction strategies that foster parasocial relationships and the potential mediating impact of parasocial relationships on the endorsement outcomes. On top of that, the existing studies mostly employed the linear assumption and variance-based approach in probing the phenomenon, thereby presenting an over-simplistic comprehension of the phenomenon as the complexity of consumer perception and behavior in exposure to influencer marketing are not being sufficiently captured (Pappas and Woodside, 2021). These gaps in knowledge spurred the present study to undertake a combined linear and non-linear approach to uncover the complexity of content and interaction strategies, as well as parasocial relationships in cultivating influencer endorsement outcomes.

\subsection{Theoretical development}

We lean on the tenet of stimulus-organism-response (S-O-R) framework (Mehrabian and Russell, 1974), supported by social cognitive theory (Bandura, 2001) and meaning transfer model (McCracken, 1989) to develop an overarching research model. The S-O-R framework suggests that exposure to some external environmental stimuli triggers an individual's emotional and cognitive reactions, which eventually result in a particular behavioral outcome. The S-O-R framework encompasses three components, namely stimulus, organism, and response. The stimulus component refers to the external influence that affects an individual's internal states. In the present study, the content attributes (i.e., attractiveness, prestige, and expertise) and interaction strategies (i.e., interactivity and self-disclosure) are considered stimuli that could evoke consumers' internal states. Past studies advocated that these factors are influence attempts taken by social media influencers in reinforcing the persuasiveness of communication and influencer-fans relationships, and consumers inevitably exposed to these influence attempts when they follow the influencers' social media account (Jun and Yi, 2020; Ki et al., 2020). The organism component refers to consumers' internal evaluations of the stimuli. Parasocial relationships were modeled as an intermediary in explaining consumers' affective/emotional reactions when interacting with a social media influencer. This is supported by the social cognitive theory of mass communication which postulates that the symbolic world portrayed by the mass media gives significance to vicarious influence by media mediated characters, from which consumers acquire lasting attitudes, and determine their emotional 
reactions (Bandura, 2001). The extended parasocial interaction theory further fortifies this view by articulating verbal and non-verbal cues on social media as the driver of parasocial relationships (Horton and Wohl 1956; Labrecque, 2014), thereby supporting our rationalization of content and interaction strategies as parasocial relationships-building tools for social media influencers. Lastly, the response component of the S-O-R framework denotes consumers' behavioral outcome (approach vs. avoidance), that is, purchase intention engendered due to parasocial relationships. Grounded in the meaning transfer model (McCracken, 1989), feeling constitutes a part of the meanings to be transferred from influencers to their endorsing brand, and consumers often pursue the endorsed brands for symbolic meaning appropriation (Aw and Labrecque, 2020). In essence, the integration of theories facilitates this study to unpack the internal mechanisms salient to the endorsement outcome which are otherwise infeasible with the employment of a singular theory. Figure 1 illustrates the proposed research model.

\subsection{Parasocial relationships}

As a concept pioneered by Horton and Wohl (1956), parasocial relationships refer to a form of one-sided emotional relationship engendered between the audience and media characters through initial or repeated interactions in the media reality, which imitate an imaginary interpersonal relationship. The applicability of parasocial relationships has been stretched from the traditional mass media to the modern online environment, especially in the social media context which brings the audience and media characters closer than ever (Labrecque, 2014). Parasocial relationships have been applied to understand the relationships between influencers, including traditional celebrities and social media influencers, and consumers in the digital environment (Breves et al., 2021; Chung and Cho, 2017; Reinikainen et al., 2020; Sokolova and Kefi, 2020; Yuan and Lou, 2020). Yuan et al. (2021) further extended parasocial relationships into the business-to-business (B2B) context, suggesting B2B parasocial relationships generated with an entrepreneur endorser stimulate repurchase intention from customer firms.

Similar to the development of interpersonal relationships, the formation of parasocial relationships undergoes the initiation-experimentation-intensification-integration process, as outlined by Knapp’s model of interpersonal relationships (Knapp et al., 2014; Tukachinsky and Stever, 2019). Therefore, akin to social relationships in real life, parasocial relationships can be established and reinforced through influencer-fans interactions (Breves et al., 2021). In 
the social media environment, consumers can engage with their favorite influencers (e.g., follow, like, comment, and share posts), thereby facilitating the impression of two-sided interactions. Authors of past studies have evidenced that frequent social media interactions between consumers and celebrities foster the development of parasocial relationships (Aw and Labrecque, 2020; Chung and Cho, 2017). A mainstream of research in the field aims to identify whether and how parasocial relationships can be translated into favorable marketing outcomes. Parasocial relationships have been found to positively influence evaluation towards a brand endorsed by an influencer (Hwang and Zhang, 2018). Breves et al. (2021) revealed that a higher level of parasocial relationships reduces consumers' critical evaluation of advertising content. Grounded in the meaning transfer model (McCracken, 1989), a few studies demonstrated the mechanism that explains the appeal of parasocial relationships, of which the feeling of influencer-fans intimacy can indeed be transferred into biased favorable perception towards the influencer and indirectly to the endorsed brands (Aw and Labrecque, 2020; Reinikainen, et al., 2020).

H1: Parasocial relationships positively influence purchase intention.

\subsection{Attractiveness}

According to Byrne et al. (1971), attraction is a fundamental aspect of all interpersonal relationships. As evidenced in the social psychology literature, the stereotype of "what is beautiful is good" has been prevalently demonstrated in our life, in which physically attractive people are inferred to possess a range of positive personal qualities (Eagly et al., 1991), endowed with aspirational and persuasive powers (Raven, 1965; Till and Busler, 2000). Correspondingly, the source attractiveness model has enjoyed decades of popularity in the influencer marketing literature where scholars consistently found the attractiveness of influencer endorsers as a crucial determinant of attitude towards advertising and the endorsed brand (Lou and Yuan, 2019; Ohanian, 1990; Schimmelpfennig and Hunt, 2019). More importantly, the authors of past studies found that consumers tend to develop illusionary intimacy with influencers who are physically attractive (Gong and Li, 2017; Yuan et al., 2016). In this study, we define attractiveness as the visual attractiveness of an influencer's social media content (Aw and Chuah, 2021). We posit that the effects of attractiveness as a personal characteristic can be extended into and reflected in their content to influence consumers. This is because the attribute of attractiveness is not only confined to social media influencers' 
personal physical appearance in real life but irrevocably permeates into their social media content. Consumers tend to follow these aesthetically pleasing content to fulfill their psychological need for ideality and facilitate emotional bonding (Ki et al., 2020). Based on the reasoning above, we posit:

H2: Attractiveness positively influences parasocial relationships.

\subsection{Prestige}

Grounded in the self-identity theory, individuals are aspired by the desire for self-enhancement, which motivates them to connect their identities with social categories (Abrams and Hogg, 2004). In this respect, people tend to associate their identities with prestigious and reputable entities. This connection between prestige and identification has been verified in the organizational behavior context, where studies found that organizational prestige image shapes employees' affective commitment, identification, and citizenship behavior (Carmeli, 2005; Dutton et al., 1994). In a similar vein, marketing literature has demonstrated that the development of consumer-brand relationships hinges upon perceived brand qualities, inferring the "bask in reflected glory" cognition (Bairrada et al., 2018; Tuškej and Podnar, 2018). For example, Bairrada et al. (2018) showed that consumers utilize prestigious corporate brands for self-expressive purposes and feel the brands as part of their integral self, thereby enticing identification. Transferring the idea to the influencer context, the attribute of prestige represents the symbolic and social capital of celebrities which in turn determine followers' admiration and perception (Aleti et al., 2019; Knoll and Matthes, 2017). Ki and Kim (2019) revealed that social media influencers' prestige content evokes consumers' desire to mimic, manifesting the engendering of rapport and close connection. In support of this, Lo (2008) indicated prestige as a pivotal cue for interpersonal attraction, of which people seek to build relationships with prestigious others to elevate self's social status as perceived by others. Hence, we hypothesize:

H3: Prestige positively influences parasocial relationships.

\subsection{Expertise}

Psychological motivation theory provides an overarching mechanism for the development of effective social media content strategies to enhance content popularity and liking (Swani et al., 2017). In particular, people respond to, engage, and transmit social media content to satisfy 
their motivation needs. One of the intrinsic psychological needs in the influencer marketing realm is the need for competence (Ki et al., 2020; Thomson, 2006). In this respect, Ki and Kim (2019) indicated social media influencers' curated content as an important information source that consumers turn to in facilitating purchase judgment and decisions, which leads to the fulfillment of their need for competence. The authors further introduced expertise as a social media influencers' content attribute, manifesting the quality of greater knowledge and/or experience in a particular aspect compared to others (McQuarrie et al., 2013). Source expertise has received well-recognition in the field as an essential driver for endorsement and relational outcomes (Lou and Yuan, 2019; Sakib et al., 2020; Schimmelpfennig and Hunt, 2019; Wang et al., 2021). Notably, expertise is an important factor determining interpersonal interaction and attraction in a computer-mediated environment (Shen et al., 2010). In the social commerce context, it has been demonstrated that consumers are gravitated towards interacting with and developing parasocial relationships with other knowledgeable users (Xiang et al., 2016). Social media influencers' expertise is manifested in their content when they share their knowledge (e.g., fitness and fashion) on social media, and the display of expertise is seen as an attempt that attracts and inspire followers, fulfill followers' needs, and ultimately results in the development of a strong interpersonal relationship (Aw and Chuah, 2021; Ki and Kim, 2019).

H4: Expertise positively influences parasocial relationships.

\subsection{Interactivity}

Influencer interactivity is manifested in the engagement of two-way communications (e.g., comments and feedback) between influencers and followers on social media (Jun and Yi, 2020). The permeation of social media into individuals' lives opens unprecedented opportunities for influencer marketing, whereby social media influencers are enabled to reach and engage with a wide range of consumers conveniently and faster than ever. More importantly, social media as the new frontier of marketing communication channels has pulled influencers and consumers closer by offering a platform for real-time interaction (Aw and Labrecque, 2020). For instance, consumers not only can interact (i.e., follow, like, share, and comment) with their favorite social media influencers but also send direct messages to them.

Unlike interactivity in traditional brands (e.g., Nike and Mercedes) or human brands (e.g., traditional celebrities and politicians), interactivity is seen as a unique strength of social media influencers and an indispensable core for them to generate positive endorsement 
outcomes (Jun and Yi, 2020). According to Jun and Yi (2020), interactivity is less prominent in the traditional celebrities context because (i) consumers are often aware that their interactions with traditional celebrities in social media are largely not originated from celebrities themselves but the account administrators, (ii) two-way communications between top-tier celebrities and consumers are extremely limited, and (iii) traditional celebrities do not rely on social media communication but more on institutional mediation for self-promotion. In contrast, social media influencers are ordinary social media users who cultivate and legitimize their influencers' status through intense active interactions with followers, and frequent interactions on social media are the sole way for them to forge a psychological connection with others (Jun and Yi, 2020; Tafesse and Wood, 2021).

In the past, influencer interactivity has been revealed as the key to stimulating consumers' purchase intention and loyalty towards the endorsed brands, particularly through the formation of brand awareness and trust (Jun and Yi, 2021; Liu et al., 2020). In the present study, we extend prior research and argue that influencer interactivity is the cornerstone for bolstering parasocial relationships. Repeated high-quality interactions help to alleviate interpersonal uncertainty and provide the foundation for attachment fortification between influencers and consumers (Aw and Labrecque, 2020; Jun and Yi, 2020; Thomson, 2006; Yuan and Lou, 2020). A handful of studies on consumer-brand relationships indirectly support this view by evidencing high interactivity in brand-consumers communication on social media as a driver to heightened relationship quality (Fang et al., 2021; Labrecque, 2014). Chung and Cho (2017) found that communicating directly with a celebrity through social media engenders a sense of personally knowing the celebrity. The interactivity of social media influencers is comparatively more intense given they actively engage with their followers (e.g., personal reply to audience comments and arrangement of offline meetups), which is expected to facilitate illusions of intimacy and friendships (Lou, 2021).

H5: Interactivity positively influences parasocial relationships.

\subsection{Self-disclosure}

Rooted in the communication literature, self-disclosure refers to "the process of making self known to others” (Jourard and Lasakow, 1958, p. 91). In other words, self-disclosure is manifested when one reveals personal information, including ideas, feelings, attitudes, and values to others through interpersonal interactions (Cozby, 1973; Wheeless and Grotz, 1977). 
Self-disclosure can be reflected in terms of breadth and depth. Breadth refers to the number of disclosed areas while depth refers to the level of intimacy concerning the information revealed (Derlega et al., 2008). According to the social penetration theory (Altman and Taylor, 2019), self-disclosure constitutes an important part of human relationships development. Past studies have shown several relational outcomes of self-disclosure, such as empathy, relationship closeness, and emotional support (Greene et al., 2006; Mangus et al., 2020). Self-disclosure is more related to and manifested to a greater extent among social media influencers compared to traditional celebrities, in which Nouri (2018) reveals that social media influencers who are seen as ordinary peers are more engaged in sharing personal information and footage of daily activities. On one hand, traditional celebrities tend to harness social media for sharing endorsement content.

Having an intimate conversation characterized by high self-disclosure involves the sharing of private personal information which promotes a deeper understanding of disclosing party's inner state, and more importantly, inferring the disclosing party's trust and liking towards the audiences (Sprecher et al., 2013). Recent studies highlight that self-disclosure has an indispensable role in influencer marketing whereby it facilitates the formation of feelings of authenticity and friendliness, which is crucial to endorsement effectiveness (i.e., purchase intention) (Kim, 2021; Leite and Baptista, 2021). Intimate self-disclosure on social media, when perceived as appropriate, has a positive impact on relationship closeness and social attraction (Lin and Utz, 2017). Social media influencers constantly generate and share narrations of their personal lives, emotion, and highly opinionated statements on social media, thereby not only enhancing perceived social presence but also evoking perceived intimacy (Aw and Chuah, 2021; Feng et al., 2020; Lou, 2021).

H6: Self-disclosure is positively related to parasocial relationships.

Insert Fig 1 About Here

\subsection{Embracing the complexity and configuration theory}

In the present study, we seek to unravel the configurations of causally related sets of causal conditions and examine the interrelationships between content attributes (i.e., attractiveness, prestige, and expertise), interaction strategies (i.e., influencer interactivity and self-disclosure), 
and parasocial relationships in predicting high purchase intention (See Fig 2). Content attributes, interaction competence, and relationship quality have been heralded as three primary drivers to endorsement outcomes in the social media influencer marketing context, in which they present simultaneously and are inter-related in the influencer strategic communication (Aw and Chuah, 2021; Enke and Borchers, 2019). Therefore, these causal conditions can be coalesced in various configurations in explaining the endorsement outcome (i.e., purchase intent). For instance, consumers are likely to purchase the endorsed products from a social media influencer who posts attractive content, interacts actively and develop relationships with consumers, while they might still purchase if the influencer does not engage in interpersonal communication but the influencer' content exhibit prestige and expertise which give reassurance. On one hand, consumers may exhibit high purchase intention on an endorsed brand based on the development of parasocial relationships and intense interactions with their favorite social media influencer, which sufficiently induce meaning transfer and fulfillment of the need for belonging (Aw and Labrecque, 2020). The identification with influencers compels consumers to engage in biased cognitive processing that favors the influencers' endorsement and behavior. As a result, content attributes might not be necessary conditions when a relationship triumphs. Based on the reasoning above, the following proposition is put forth:

Proposition 1: No single best configuration of content attributes, interaction strategy, and parasocial relationships leads to high purchase but there exist multiple, equally effective configurations of causal conditions.

-Insert Fig 2 About Here-

\section{Methodology}

\subsection{Data collection method and sample}

The data was collected using an online questionnaire survey approach. In line with prior influencer literature (Hu et al., 2020; Reininaiken et al., 2020), we recruited the respondents by sharing a link to the survey on multiple social media networking sites. A purposive sampling technique was applied, of which only people who have a social media account and have followed social media influencers are eligible to participate in the survey. Following the approach taken by prior research (Aw and Chuah, 2021; Jun and Yi, 2020), respondents were 
briefed with the definition of social media influencers to increase the accuracy of responses obtained from the respondents. Subsequently, respondents were asked to recall a favorite social media influencer they follow and answer a series of questions about the focal constructs. Social desirability bias was minimized by ensuring the anonymity of the question-and-answer process (i.e., no presence of the interviewer and bystanders, no personally identifiable information was collected, and none of the collected data will be disclosed) (Foo et al., 2021; Krumpal, 2013). Moreover, in order to ensure the data quality and rigor, we performed a t-test by comparing the responses acquired between early and late respondents (Foo et al., 2021). The findings turned out that there is not a statistically significant difference between the responses, indicating that non-response bias is unlikely a threat to the study. A total of 411 usable responses were collected over two months after discarding suspicious responses. $62 \%$ of respondents were female. The majority of them were students (58.9\%) and aged 18-25 years (65.2\%).

\subsection{Measures}

The measurement items were adapted from the established literature to suit the context of this study. Ki and Kim's (2019) study was used to obtain measurements for content attributes, including attractiveness, prestige, expertise, and purchase intention. The measurement of parasocial relationships and self-disclosure were adopted from Chung and Cho (2017). The measurement for interactivity was adopted from Jun and Yi (2020). All items were measured using a seven-point Likert scale, of which 1 was anchored by "strongly disagree" and 7 was anchored by "strongly agree".

\section{Data analysis}

\subsection{Symmetric analysis}

To test the proposed model, we employed both symmetric and asymmetric analyses to gain a holistic understanding of the phenomenon because recent literature has advocated that although taking asymmetric perspective (i.e., variance-based approach) enable researchers to pinpoint general tendencies and important predictors of an outcome of interest, the approach falls short by overlooking the facts that the relationships among variables are inherently complex and sometimes nonlinear, particularly involving human behavior (Pappas and Woodside, 2021). Therefore, we adopted the fuzzy-set qualitative comparative analysis as an asymmetric analysis tool to yield more insights into the data. 
For symmetric analysis, we applied partial least squares structural equation modeling (PLS-SEM). PLS-SEM has received wide recognition in the information system and marketing field, and it is suitable because: (i) our study is prediction-oriented (i.e., identifying factors influencing purchase intent), (ii) minimal requirement in terms of sample size, measurement model, and data assumptions, (iii) the research model is complex and involves many constructs and indicators, (iv) the research orientation leans towards theory extension/exploration rather than theory confirmation (e.g., integration of the S-O-R framework, parasocial interaction theory, and meaning transfer model), and (v) latent variable scores are needed for subsequent analysis (Hair et al., 2017; Hair et al., 2019). We performed a multivariate normality analysis and found multivariate non-normality in the dataset, with Mardia's multivariate skewness $(\beta=$ 5.103, $p<0.01)$ and multivariate kurtosis $(\beta=74.507, p<0.01)$. The finding fortified the rationale for adopting PLS-SEM in the present study. We executed PLS-SEM analysis following the two-stage analytical procedure, whereby the measurement model was examined before the structural model.

Before entering formal PLS-SEM analysis, we assessed common method bias by using Harman's single-factor test (Podsakoff et al., 2003). The result turned out that the first factor explains $35.21 \%$ of the total variance, below the threshold of 50\% (Podsakoff et al., 2003). Next, we adopted the correlation matrix procedure (Bagozzi and Yi, 1991) and found that the highest inter-construct correlation was 0.632 , well below the 0.90 cut-off value. In addition, we performed the full collinearity test as suggested by Kock (2015). The result showed that the variance inflation factor (VIF) values were between 1.391 and 2.102, which were below the 3.3 thresholds. Finally, following the approach taken by prior research (Liang et al., 2007; Tan and Ooi, 2018), we included a common method factor in the model and calculated the substantive factor loading $\left(\mathrm{Ra}^{2}\right)$ and method factor loading $\left(\mathrm{Rb}^{2}\right)$. The results turned out that all items in $\mathrm{Ra}^{2}$ are significant at $p<0.01$. More importantly, the average of $\operatorname{Ra}^{2}(0.721)$ was substantially higher than the average of $\mathrm{Rb}^{2}(0.014)$ (Leong et al., 2020) To sum up, the findings from four tests conducted suggest that common method bias was unlikely a major threat in this dataset.

\subsubsection{Measurement model}

The measurement model was examined through the computation of indicator loadings, composite reliability, average variance extracted (AVE), and the heterotrait-monotrait ratio of 
correlations (HTMT) (Hair et al., 2019). As exhibited in Table 1, the composite reliabilities and AVEs for all constructs were above the 0.70 and 0.50 threshold, respectively. Indicator loadings for all constructs ranged between 0.627 and 0.941. According to Hair et al. (2019), indicator loadings between 0.40 and 0.60 are acceptable and should be retained to preserve content validity under the condition that the construct convergent validity and internal consistency were satisfied. In short, convergent validity was established. Subsequently, we employed the HTMT criterion to assess discriminant validity (Henseler et al., 2015). As demonstrated in Table 2, all HTMT values were below the conservative cut-off of 0.85 (Kline, 2011). Further, Table 3 depicted that square root AVEs for all constructs exceeded their correlations with other constructs. Combinedly, the two tests conducted suggest the establishment of discriminant validity (Hair et al., 2019).

-Insert Table 1 About Here

-Insert Table 2 About Here

Insert Table 3 About Here

\subsubsection{Structural model}

Before testing the proposed hypotheses, we conducted a collinearity test to rule out the threat of multicollinearity (Hair et al., 2019). The result showed that VIF values of all constructs were in the range between 1.332 and 2.091, indicating the absence of multicollinearity issue. The structural model was assessed by examining the path coefficients and significance levels. The bootstrapping technique with 5,000 sub-samples was applied. With regards the effect of content attributes, prestige $(\beta=0.100 ; p<0.05)$ and expertise $(\beta=0.134 ; p<0.05)$ showed significant positive impacts on parasocial relationships. However, the impact of attractiveness on parasocial relationships was insignificant $(p>0.05)$. With regards to the interaction strategies, influencer interactivity $(\beta=0.415 ; p<0.05)$ and self-disclosure $(\beta=0.195 ; p<0.05)$ significantly influenced parasocial relationships. Parasocial relationships had a significant positive impact on purchase intention $(\beta=0.192 ; p<0.05)$. We further performed a post-hoc mediation using the bias-corrected bootstrap confidence interval approach (Nitzl et al., 2016). Findings suggested that parasocial relationships are a significant mediator in the relationships between all predictors (i.e., prestige, expertise, interactivity, and self-disclosure) except attractiveness, and purchase intention, with no 0 straddle in between 95\% confidence interval. The model exhibited an $\mathrm{R}^{2}$ of 0.457 for parasocial relationships and 0.296 for purchase 
intention. In addition, we assessed the model's out-of-sample predictive accuracy by using the PLSpredict technique (Hair et al., 2019). The prediction errors (i.e., RMSE and MAE) for all key endogenous construct indicators (i.e., purchase intention) were lower in PLS-SEM analysis compared to the naïve LM benchmark, suggesting the high predictive power of the model.

-Insert Table 4 About Here

-Insert Table 5 About Here

\subsection{Asymmetric analysis}

Fuzzy-set qualitative comparative analysis (FsQCA) was adopted to offer an alternative view to the findings from PLS-SEM which is largely based on symmetric assumptions and identification of net effect between competing variables in a model (Pappas and Woodside, 2021). Unlike the variance-based approach, fsQCA derives multiple pathways by identifying the complex and asymmetric relations between causal conditions and the outcome of interest. As a result, authors of extant studies advocated the combination use of variance-based approach and fsQCA to yield a more enriching understanding of the phenomenon (Pappas and Woodside, 2021; Schneider and Wagemann, 2010). As noted in prior literature, fsQCA is useful for both inductive and deductive reasoning and thus can accommodate theory testing, building, and elaboration (Park et al., 2020). Given the complex patterns of causal interrelationships between content attributes, celebrity-fan interactions, and parasocial relationships, we see the value of fsQCA in facilitating a better understanding of the underlying causes of the outcome (i.e., purchase intention).

\subsubsection{Calibration}

The set membership theory embedded in fsQCA entails the conversion of ordinal or interval scales into membership score sets, ranging from 0 (fully non-member of a fuzzy set) to 1 (full member of a fuzzy set), with 0.5 as a crossover point or known as intermediate set (Ragin, 2008). We transformed the latent variable scores into fuzzy set membership scores by applying the 95th percentile as an anchor for full membership, 50th percentile as the cross-over point, and 5th percentile as an anchor for full non-membership (Rasoolimanesh et al., 2021). 


\subsubsection{Identifying the configurations}

We followed Ragin's (2000) suggestion to assess necessity before sufficiency. By testing each causal condition independently, we found that the highest consistency is 0.77 , which was below the cut-off value of 0.90 . Therefore, no necessary condition was identified. Subsequently, we ran the fuzzy set algorithm using the fsQCA 3.0 software to construct a truth table of $2^{k}$ rows ( $k$ represents the number of independent variables and each row denotes a possible combination). Next, we refine the truth table by removing rows that did not meet the frequency threshold of 5. As recommended by Fiss (2011), the threshold could be defined at 2 for smaller samples (<100), and should be increased (3 or higher) for a larger sample $(>150)$. Next, we removed configurations with a consistency value below 0.90 breaking point. The fsQCA findings offer three main outputs, namely complex, parsimonious, and intermediate (see Ragin (2008) for details). The intermediate solution was chosen as it is deemed more superior in terms of completeness and interpretability (Rasoolimanesh et al., 2021). Six configurations that lead to high purchase intention were revealed and discussed in the next section. Consistency and coverage are the two important metrics in interpreting the fsQCA results and determining the usefulness of the model. Analogous to correlation, consistency denotes the degree to which observed configurations are consistently linked to the outcome, whereas coverage evaluates the empirical relevance of a consistent subset, which is comparable to $\mathrm{R}^{2}$ in regression (Ragin, 2008). As shown in Table 5, every configuration and overall solution exhibited a high degree of consistency ( $>0.75$ ) and coverage ( $>0.20$ ) (Rasoolimanesh et al., 2021). The overall solution coverage (0.685) indicated that a considerable amount of outcome is explained by the six configurations identified.

-Insert Table 6 About Here

\subsubsection{Predictive validity and robustness test}

According to Pappas et al. (2021), the assessment of predictive validity is essential because a good model fit does not equate to good predictions, and predictive validity helps to understand the power of the model in predicting the dependent variable in different samples. We first split the sample into a subsample and a holdout sample randomly. The fsQCA analysis was performed for the subsample, and the findings generated were tested against the holdout sample. In this stage, each solution that encompasses different combinations of present and absent 
causal conditions was modelled as one variable and plotted against the targeted outcome using the holdout sample. As illustrated in Fig. 3, the findings for testing model 1 against purchase intention with data from the holdout sample suggested high consistency (0.874) and coverage (0.458). Further predictive tests were conducted for the remaining models, and it was found that suggests that the subsample models show high predictive power for the holdout sample and vice versa, for high purchase intention. We further conducted a robustness check by using different percentile thresholds (e.g., $90 / 80^{\text {th }}, 50^{\text {th }}$, and $10 / 20^{\text {th }}$ ). The results indicate minor variations in the solutions and result in no major changes in terms of interpretation. All results are available upon request.

Insert Fig 3 About Here

\section{Discussion}

Advertisements have permeated into every aspect of consumers' life (Tan et al., 2018), compelling them to be more vigilant and selectively attentive than ever in dealing with the overwhelming ad exposures. Importantly, smart consumers look through the persuasive attempts of brands and know-how to shun those overtures, in which they often see advertisements and brand-generated content less credible and authentic compared to online word-of-mouth (Campbell and Farrell, 2020). Correspondingly, consumers are increasingly turning to social media influencers who are seen as key opinion leaders and trusted content creators. Hence, the meteoric stardom and social relationships possessed by social media influencers imply huge and lucrative business opportunities that brands are pursuing. Despite the ubiquity of influencer marketing, it remains unknown how brands and social media influencers curate their content and manage their self-presentation to foster parasocial relationships with consumers and achieve better endorsement outcomes. In the present study, grounded in symmetric and asymmetric thinking, we strive to develop an understanding of this matter by examining the inter-relationships between content attributes, interaction strategies, parasocial relationships, and purchase intention.

The results generated from PLS-SEM unravel and shed light on the understanding of the underlying mechanism of how social media influencers' content attributes and interaction strategies lead to endorsement outcomes (i.e., purchase intent) through the formation of parasocial relationships. Interestingly, the findings suggest that influencers' social media content needed to be crafted in a way that manifests the sense of prestige and expertise. Akin 
to traditional celebrities, people are attracted to social media influencers' quality of cognitivebased credibility not only for purchase judgment but also meaning appropriation, including that shaping of feeling and identity (Boon and Lomore, 2001; Kaikati, 1987). The finding conforms to the social psychology literature indicating that people who deploy prestige strategy and demonstrate competence tend to be more socially accepted, able to grab social attention and induce liking by others (Cheng et al., 2013). In addition, the finding further extends and reinforces the interpersonal attraction theory by highlighting the fact that attributes a source/person possesses can be reflected through digital content and their power is further augmented to have far-reaching influence in building illusionary intimacy with plenty of others. One disquieting result of our research is the insignificant effect of content attractiveness on parasocial relationships, which is inconsistent with that of past studies (Aw and Chuah, 2021; Lou and Yuan, 2019). One plausible reason is that these studies did not take into account the components of influencer-fans interaction which overwhelm the power of content attractiveness. Besides, Kim and Kim (2021) discovered that attractiveness is an effective cue for positive initial judgment but not in facilitating relatively long-term interactions (i.e., parasocial relationships) between influencers and consumers.

Apart from the curated content, a careful orchestration of a likeable online persona requires social media influencers to understand and exert more effort in their interaction with followers. Past studies have advocated the intensity of social media interactions between celebrities and consumers as a key determinant in fostering parasocial relationships (Aw and Labrecque, 2020; Chung and Cho, 2017). In advancing this line of research, our findings reveal two relevant interaction strategies, namely interactivity and self-disclosure. Interactivity is a unique feature of social media influencers that shape consumers' perceived authenticity emotional attachment towards them (Jun and Yi, 2020). Unlike in the past, consumers today expect a direct two-way communication and timely reaction from influencers, including social media influencers and traditional celebrities, of which they wish to feel affiliated to influencers and want their voice to be listened to and responded to (Argyris et al., 2020; Aw and Labrecque, 2020; Jun \& Yi, 2020). On top of that, in line with prior studies (Chung and Cho, 2017; Ferchaud et al., 2018), we reveal that social media influencers can harness the self-disclosure strategy to develop parasocial relationships with consumers. To clarify, the formation of parasocial relationships in digital media mimics the trajectory of interpersonal relationship development, entailing adequate self-disclosure to reduce relationship uncertainty and emotional investment (Ferchaud et al., 2018; Perse and Rubin, 1989). The significant positive 
impact of parasocial relationships on purchase intention is within expectation and is in good agreement with previous studies (Shan et al., 2020; Sokolova and Kefi, 2020).

The application of fsQCA demonstrates potential superiority over the linear-based PLSSEM in dealing with causal complexity by elucidating how content attributes, interaction strategies, and relational factors interplay and combine in achieving purchase intention. Solution 1 and 2 suggest that the simultaneous presence of attractiveness, expertise, and prestige can fuel purchase intention, with a subtle difference in the substitute between parasocial relationships and self-disclosure, thereby lending support to the study by Aw and Chuah (2021). Solution 3 reveals that attractiveness can yield high purchase intention when combined with the presence of interaction strategies (i.e., interactivity and self-disclosure) and parasocial relationships. The finding substantiates the idea of recent influencer literature that the influencer endorsement landscape is shifting from one-way communication (i.e., source effect) towards more intense two-way interactions that emphasize influencer-consumers relationships and interactions (Moraes et al., 2019; Reinikainen et al., 2020). Interestingly, attractiveness identified as an insignificant predictor in the PLS-SEM manifests its relevance in three causal recipes as a peripheral causal condition, indicating additional insights offered by FsQCA in complementing “net effect” results computed through a variance-based method.

Of more importance, we uncover some interesting findings from solution 5 and solution 6. Solution 5 indicates that high purchase intention can still be fostered through expertise, parasocial relationships, and self-disclosure in the absence of attractiveness and influencer interactivity. The solution resonates with the key idea of "who says what" in the influencer marketing context, in which consumers are interested in their identified influencers' personal life and meanwhile influencers are leveraging on this opportunity to engage in self-disclosure while integrating informative communication (e.g., product usage experience). This personal approach simultaneously amplifies the power of perceived expertise and opinion leadership (Farivar et al., 2021). Similarly, solution 6 suggests that in the absence of expertise and prestige, positive influencer endorsement outcomes can be achieved through the presence of influencer interactivity, self-disclosure, and parasocial relationships. The findings reinforce the mediating effect of parasocial relationships between content attributes, interaction strategy, and purchase intention. The solution well-reflects the reciprocity principle (Altman, 1973) and uncertainty reduction theory (Berger and Calabrese, 1975). To clarify, the one-sided illusionary parasocial relationships compel consumers to draw positive inferences of social media influencers' endorsement but the pseudo-relationships typically lack reciprocity of which the interactions 
are limited to one-way communication, leaving withdrawal as the sole option if conusmers are dissatisfied with the interaction experience. Self-disclosure and interactivity may come into play as a reinforcement given that the disclosure of personal details by social media influencers and active interactions with consumers are seen as a form of social rewards that prompt reciprocation with positive evaluations (Leite and Baptista, 2021). Notably, self-disclosure and interactivity foster likability and trust (Chung and Cho; 2019; Jun and Yi, 2020). Jointly, the solution manifests a viable influencer marketing route that taps into consumers' emotion and relational closeness which is powerful enough to substitute cognitive evaluations towards content, implying that mastering the art of creating a meaningful connection lies at the heart of a successful influencer marketing.

As shown in Table 5, parasocial relationships emerge as a core causal condition in five out of six solutions. Influencer marketing is on the verge of a revolution where relational and interaction factors are thrust into the limelight (Hu et al., 2020). Grounded in the social learning theory, social media influencers with whom consumers have parasocial relationships are seen as "super peers" and accepted into their social network, thus their directives and messages are in general more receptive (Hwang and Zhang, 2018; Tukachinsky et al., 2020). Apart from curating quality social media content and advertisement, social media influencers and brands should step up their game by proactively interacting with and opening up their lives to the followers in order to cultivate parasocial relationships, with the ultimate aim of attaining desirable endorsement outcomes (i.e., purchase intention).

To sum up, complementing the "general tendency" findings of PLS-SEM, the uptake of fsQCA returned six configurations with the combination of content attributes (i.e., attractiveness, prestige, and expertise), interaction strategies (i.e., interactivity and selfdisclosure), and parasocial relationships to achieve high purchase intention in the influencer marketing context. These novel findings resonate with proposition 1 , implying that the focal should not be directed in identifying a single best factor that yields high purchase intention, instead, different effective pathways can be taken. In the end, there is no definite answer to whether certain attributes such as attractiveness or prestige should be emphasized, rather their unique prominence is contextualized, in conjunction with the presence or absence of other conditions. For instance, although the attribute of content expertise is unarguably imperative in influencer marketing, it is still possible for influencers and marketers to stimulate purchase intention in the absence of content expertise by leveraging a combination of other attributes and interaction strategies. Thus, the findings propel the adoption of a 'mix-and-match' 
approach that yields optimal mixtures of content attributes, interaction strategies, and parasocial relationships.

\subsection{Theoretical implications}

Firstly, the results of the study add to the growing body of evidence that parasocial relationships are driven by the source effect model, such as attractiveness and popularity (Sokolova and Kefi, 2020; Yuan et al., 2021; Zhang et al., 2020). Unlike traditional celebrities, social media influencers as the new market maven in the digital age, are gaining traction by being closely connected to their followers and disseminating shared value and ideas, through their social media content. In like manner, we delineated that the source effect of influencers is manifested and transmitted through their content, and these content attributes are paramount in explaining parasocial relationships. Secondly, in enriching the existing literature, we further unveiled the power of interactivity and self-disclosure as effective strategies that exert a real bearing on prosocial relationships development and ultimately reinforce purchase intention. Thirdly, another contribution of this study stems from our proposition that various configurations and asymmetric relations among the proposed variables explain the outcome of interest (i.e., purchase intention). Although a few emerging studies have offered empirical evidence pertaining to the impact of influencers' content and interaction features on certain endorsement outcomes (Aw and Chuah, 2021; Jun and Yi, 2020), these studies typically focus on the "net effect" of different antecedents on an outcome but overlook the possible interdependencies between those antecedents. Due to the limited power of the traditional regression-based approach in explicating higher-order interactions, the inherent complexities of consumer behavior in realities are uncaptured. Drawing from the complexity theory and configuration theory, our study represents the pioneering attempt to demonstrate how content attributes, interaction strategies, and parasocial relationships can be interrelated and combined to explain purchase intention. More specifically, we discerned six configurations that combine attractiveness, expertise, prestige, influencer interactivity, self-disclosure, and parasocial relationships in a complex causal pattern, which leads to purchase intention. Therefore, we help to paint a more nuanced and complete picture by evidence that there is no single best solution but there exist multiple solutions salient to the formation of purchase intention in the context of social media influencer marketing. 


\subsection{Practical implications}

The findings of this study can help marketers in formulating strategic practice of social media influencer marketing. The emergence of social media has empowered people, in general, to create and disseminate content at an unprecedented scale, resulting in a massive influx of social media influencers and intense competition among them to draw public attention and create fame. In today’s marketing environment, which some termed “attention economy”, marketers need comprehensive insights in influencer selection and collaboration rather than engaging influencer marketing for the fear of missing out. Unlike in the past, today's influencer marketing entails selecting influencers beyond traits and physical appearance. Instead, building close influencer-consumers relationships organically is at the nexus of modern influencer marketing, where studies revealed that parasocial relationships can be an effective marketing communications tool towards achieving greater persuasion, brand credibility, and purchase intention (Aw and Chuah, 2021; Chung and Cho, 2017; Reininaiken et al., 2020). Correspondingly, it has been shown that audience relationship is the priority of consideration for marketers in selecting influencers (Influencer Marketing Hub, 2020). Accordingly, marketers should utilize relationship-oriented indicators (e.g., sentiment and engagement rate) to guide influencer selection (Arora et al., 2019). In addition, prior studies revealed that the number of followers could serve as a cue, of which micro-influencers (10,000 to 500,000 followers) are believed to have closer relationships with followers compared to their macroinfluencers counterpart (more than 500,000 followers) (Dhanesh and Duthler, 2019).

As demonstrated in this study, marketers and social media influencers should proactively cultivate and strengthen parasocial relationships through strategic content creation. The finding yielded by fsQCA provide social media influencers with some guidelines to incorporate and convey the desired qualities of social media content. Influencers' content plays an indispensable role in maintaining the relationship between endorsing brands and consumers (Lou and Yuan, 2019), and they are part of self-presentation and impression management. Marketers and social media influencers could use social media analytics and linguistic analysis to identify the essence in crafting attributes of attractiveness, expertise, and prestige into their social media content. More importantly, marketers need to realize that social media influencers are not simple attention-getting gimmicks but brand communicators or even "real friends" with whom consumers would like to interact with. Hence, instead of posting content unidirectionally, social media influencers should engage in an interactive dialogue with consumers by not only sharing product information but also personal lives and opinions which serve as 
the foundation of authenticity and intimacy. The effect could be even amplified if the social media influencers can identify the prime times of posting and optimal media format (Argyris et al., 2020). The live streaming and story feature embedded in social media present a valuable opportunity marketers and social media influencers would not want to squander. Well-crafted live streaming sessions and stories allow social media influencers to share raw and authentic moments, and enable real-time conversation and interactive activities, thereby facilitating parasocial relationships development which ultimately translates into purchase intention.

\section{Limitations and future research directions}

There are some important caveats to the study that deserves attention. First, our study is based on a cross-sectional design that prohibits causal inference. Future studies might expand on our study by employing an experimental approach or a longitudinal approach to provide more robust causal evidence (Chong et al., 2014). Secondly, although our study offers insight on relevant content attributes in relation to parasocial relationships and influencer endorsement outcomes, much remain to be explored in the area. For instance, future studies could investigate the value transmitted by the influencers' social media content, such as virility and cordiality, and their impact on consumers' perception towards influencers and endorsement-related outcomes. In addition, future studies could consider data mining approaches such as topic modeling and text-mining to identify under-explored content attributes and impression management strategies practiced by social media influencers. Thirdly, the authors of future studies could enhance our model by examining the configurational effect of different factors such as influencer image-content fit, influencer-brand fit, personal characteristics (e.g., affinity), and product characteristics (e.g., high vs. low involvement). Notably, to further advance the social media influencer literature, we advocate future studies to extend the present study by probing into the dark sides of content and interaction strategies. For instance, do consumers always favorably respond to attractive and prestigious content? Aw and Chuah (2021) raised the idea that the positive impacts might not hold when consumers experience self-concept discrepancy with a social media influencer. Similarly, a social media influencer may occasionally engage in negative self-disclosure, and it remains unknown how consumers would react to it. Lastly, we focus only on a single outcome (i.e., purchase intention). Future studies are suggested to extend the current research model with additional outcomes that cover a wider range of online behavior in response to influencer marketing, such as the consumer's online brand-related activities (COBRA) (Muntinga et al., 2011). 


\section{References}

Abrams, D. and Hogg, M.A. (2001), "Collective identity: Group membership and selfconception”, in Hogg, M. and Tindale, R. (Eds), Blackwell Handbook of Social Psychology: Group Processes, Blackwell, England, pp. 425-460.

Aleti, T., Pallant, J.I., Tuan, A. and van Laer, T. (2019), “Tweeting with the stars: Automated text analysis of the effect of celebrity social media communications on consumer word of mouth”, Journal of Interactive Marketing, Vol. 48, pp. 17-32.

Altman, I. and Taylor, D.A. (1973). Social Penetration: The Development of Interpersonal Relationships, Holt, Rinehart \& Winston, New York, NY.

Altman, I. (1973), "Reciprocity of interpersonal exchange”, Journal for the Theory of Social Behaviour, 3(2), 249-261.

Arora, A., Bansal, S., Kandpal, C., Aswani, R. and Dwivedi, Y. (2019), "Measuring social media influencer index-insights from Facebook, Twitter and Instagram”, Journal of Retailing and Consumer Services, Vol. 49, pp. 86-101.

Aw, E.C.-X. and Chuah, S.H.W. (2021), ““'Stop the unattainable ideal for an ordinary me!” fostering parasocial relationships with social media influencers: The role of selfdiscrepancy”, Journal of Business Research, Vol. 132, pp. 146-157.

Aw, E.C.-X. and Labrecque, L.I. (2020), "Celebrity endorsement in social media contexts: Understanding the role of parasocial interactions and the need to belong”, Journal of Consumer Marketing, Vol. 37 No. 7, pp. 895-908.

Argyris, Y.A., Wang, Z., Kim, Y. and Yin, Z. (2020), “The effects of visual congruence on increasing consumers' brand engagement: An empirical investigation of influencer marketing on Instagram using deep-learning algorithms for automatic image classification”, Computers in Human Behavior, Vol. 112, pp. 106443.

Bagozzi, R.P. and Yi, Y. (1990), “Assessing method variance in multitrait-multimethod matrices: The case of self-reported affect and perceptions at work”, Journal of Applied Psychology, Vol. 75, pp. 547-560.

Bairrada, C. M., Coelho, F. and Coelho, A. (2018), “Antecedents and outcomes of brand love: Utilitarian and symbolic brand qualities”, European Journal of Marketing, Vol. 52 No. 3/4, pp. 656-682. 
Bandura, A. (2001), “Social cognitive theory of mass communication”, Media Psychology, Vol. 3, pp. 265-299.

Berger, C. and Calabrese, R. (1975), “Some explorations in initial interaction and beyond: Toward a developmental theory of interpersonal communication”, Human Communication Research, Vol. 1 No. 2, pp. 99-112.

Boerman, S.C. (2020), “The effects of the standardized Instagram disclosure for micro-and meso-influencers”, Computers in Human Behavior, Vol. 103, pp. 199-207.

Boon, S.D. and Lomore, C.D. (2001), “Admirer-celebrity relationships among young adults: Explaining perceptions of celebrity influence on identity", Human Communication Research, Vol. 27 No. 3, pp. 432-465.

Breves, P., Amrehn, J., Heidenreich, A., Liebers, N. and Schramm, H. (2021), “Blind trust? The importance and interplay of parasocial relationships and advertising disclosures in explaining influencers' persuasive effects on their followers”, International Journal of Advertising. 10.1080/02650487.2021.1881237

Byrne, D., Gouaux, C., Griffitt, W., Lamberth, J., Murakawa, N., Prasad, M., Prasad, A. and Ramirez, M. (1971), “The ubiquitous relationship: Attitude similarity and attraction: A cross cultural study. Human Relations, Vol. 24, pp. 201-207.

Campbell, C. and Farrell, J.R. (2020), "More than meets the eye: The functional components underlying influencer marketing”, Business Horizons, Vol. 63 No. 4, pp. 469-479.

Carmeli, A. (2005), "Perceived external prestige, affective commitment, and citizenship behaviors”, Organization Studies, Vol. 26 No. 3, pp. 443-464.

Cheng, J.T., Tracy, J.L., Foulsham, T., Kingstone, A. and Henrich, J. (2013), “Two ways to the top: Evidence that dominance and prestige are distinct yet viable avenues to social rank and influence”, Journal of Personality and Social Psychology, Vol. 104 No. 1, pp. 103-125.

Chong, A.Y.L., Ooi, K.B., Bao, H. and Lin, B. (2014). Can e-business adoption be influenced by knowledge management? An empirical analysis of Malaysian SMEs. Journal of Knowledge Management, Vol. 18 No. 1, pp. 121-136.

Chung, S. and Cho, H. (2017), "Fostering parasocial relationships with celebrities on social media: Implications for celebrity endorsement”, Psychology \& Marketing, Vol. 34 No. 4, pp. 481-495. 
Cozby, P. C. (1973), “Self-disclosure: A literature review”, Psychological Bulletin, Vol. 79 No. 2, pp. 73-91.

De Veirman, M., Cauberghe, V. and Hudders, L. (2017), “Marketing through Instagram influencers: The impact of number of followers and product divergence on brand attitude”, International Journal of Advertising, Vol. 36 No. 5, pp. 798-828.

Derlega, V.J., Winstead, B.A. and Greene, K. (2008), "Self-disclosure and starting a close relationship”, in Sprecher, S., Wenzel, A., and Harvey, J. (Eds), Handbook of Relationship Beginnings, Psychology Press, New York, pp. 153-174.

Dhanesh, G.S. and Duthler, G. (2019), "Relationship management through social media influencers: Effects of followers' awareness of paid endorsement”, Public Relations Review, Vol. 45 No. 3, pp. 101765.

Dutton, J.E., Dukerich, J.M. and Harquail, C.V. (1994), “Organizational images and member identification”, Administrative Science Quarterly, Vol. 39 No. 2, pp. 239-263.

Eagly, A.H., Ashmore, R.D., Makhijani, M.G. and Longo, L.C. (1991), "What is beautiful is good, but...: A meta-analytic review of research on the physical attractiveness stereotype”, Psychological Bulletin, Vol. 110 No. 1, pp. 109-128.

Enke, N., \& Borchers, N. S. (2019). Social media influencers in strategic communication: A conceptual framework for strategic social media influencer communication. International Journal of Strategic Communication, 13(4), 261-277.

Escalas, J.E. and Bettman, J.R. (2017), “Connecting with celebrities: How consumers appropriate celebrity meanings for a sense of belonging”, Journal of Advertising, Vol. 46 No. 2, pp. 297-308.

Fang, Y.-H., Li, C.-Y. and Bhatti, Z.A. (2021), "Building brand loyalty and endorsement with brand pages: integration of the lens of affordance and customer-dominant logic”, Information Technology \& People, Vol. 34 No. 2, pp. 731-769.

Farivar, S., Wang, F. and Yuan, Y. (2021), “Opinion leadership vs. para-social relationship: Key factors in influencer marketing”, Journal of Retailing and Consumer Services, Vol. 59, pp. 102371. 
Feng, Y., Chen, H. and Kong, Q. (2020), “An expert with whom I can identify: The role of narratives in influencer marketing”, International Journal of Advertising. 10.1080/02650487.2020.1824751

Ferchaud, A., Grzeslo, J., Orme, S. and LaGroue, J. (2018), “Parasocial attributes and YouTube personalities: Exploring content trends across the most subscribed YouTube channels”, Computers in Human Behavior, Vol. 80, pp. 88-96.

Fiss, P.C. (2011), "Building better causal theories: A fuzzy set approach to typologies in organization research”, Academy of Management Journal, Vol. 54 No. 2, pp. 393-420.

Foo, P.Y., Lee, V.H., Ooi, K.B., Tan, G.W.H. and Sohal, A. (2021), “Unfolding the impact of leadership and management on sustainability performance: Green and lean practices and guanxi as the dual mediators”, Business Strategy and the Environment. https://doi.org/10.1002/bse.2861

Gong, W. and Li, X. (2017), "Engaging fans on microblog: The synthetic influence of parasocial interaction and source characteristics on celebrity endorsement”, Psychology \& Marketing, Vol. 34 No. 7, pp. 720-732.

Greene, K., Derlega, V.L. and Mathews, A. (2006), “Self-disclosure in personal relationships”, in Vangelisti, A. and Perlman, D. (Eds), Cambridge Handbook of Personal Relationships, Cambridge University Press, Cambridge.

Hair, J.F., Risher, J.J., Sarstedt, M. and Ringle, C.M. (2019), "When to use and how to report the results of PLS-SEM”, European Business Review, Vol. 31 No. 1, pp. 2-24.

Hair, J., Hollingsworth, C.L., Randolph, A.B. and Chong, A.Y.L. (2017), “An updated and expanded assessment of PLS-SEM in information systems research”, Industrial Management \& Data Systems, Vol. 117 No. 3, pp. 442-458.

Henseler, J., Ringle, C.M. and Sarstedt, M. (2015), “A new criterion for assessing discriminant validity in variance-based structural equation modeling”, Journal of the Academy of Marketing Science, Vol. 43 No. 1, pp. 115-135.

Hew, J.J., Tan, G.W.H., Lin, B. and Ooi, K.B. (2018), “Generating travel-related contents through mobile social tourism: does privacy paradox persist?”, Telematics and Informatics, Vol. 34 No. 7, pp. 914-935. 
Horton, D. and Wohl, R.R. (1956), "Mass communication and para-social interaction: Observations on intimacy at a distance”, Psychiatry, Vol. 19, pp. 215-229.

Hwang, K. and Zhang, Q. (2018), “Influence of parasocial relationship between digital celebrities and their followers on followers' purchase and electronic word-of-mouth intentions, and persuasion knowledge”, Computers in Human Behavior, Vol. 87, pp. 155-173.

Influencer Marketing Hub (2021), “100 influencer marketing statistics for 2021”, available at: https://influencermarketinghub.com/influencer-marketing-statistics/

Jin, S.V., Muqaddam, A. and Ryu, E. (2019), "Instafamous and social media influencer marketing”, Marketing Intelligence \& Planning, Vol. 37 No. 5, pp. 567-579.

Jourard, S.M. and Lasakow, P. (1958), "Some factors in self-disclosure”, The Journal of Abnormal and Social Psychology, Vol. 56 No. 1, pp. 91-98.

Jun, S. and Yi, J. (2020), "What makes followers loyal? The role of influencer interactivity in building influencer brand equity”, Journal of Product \& Brand Management, Vol. 29 No. 6, pp. 803-814.

Kaikati, J.G. (1987), “Celebrity advertising: A review and synthesis”, International Journal of Advertising, Vol. 6 No. 2, pp. 93-105.

Kapitan, S. and Silvera, D.H. (2016), "From digital media influencers to celebrity endorsers: Attributions drive endorser effectiveness”, Marketing Letters, Vol. 27 No. 3, pp. 553-567.

Khamis, S., Ang, L. and Welling, R. (2017), “Self-branding, 'micro-celebrity' and the rise of social media influencers”, Celebrity Studies, Vol. 8 No. 2, pp. 191-208.

Ki, C.W.C. and Kim, Y.K. (2019), "The mechanism by which social media influencers persuade consumers: The role of consumers’ desire to mimic”, Psychology \& Marketing, Vol. 36 No. 10 , pp. 905-922.

Ki, C.W.C., Cuevas, L.M., Chong, S.M. and Lim, H. (2020), "Influencer marketing: Social media influencers as human brands attaching to followers and yielding positive marketing results by fulfilling needs”, Journal of Retailing and Consumer Services, Vol. 55, pp. 102133.

Kim, H. (2021). Keeping up with influencers: exploring the impact of social presence and parasocial interactions on Instagram. International Journal of Advertising, available at: 10.1080/02650487.2021.1886477 
Kim, D.Y. and Kim, H.Y. (2021), “Trust me, trust me not: A nuanced view of influencer marketing on social media”, Journal of Business Research, Vol. 134, pp. 223-232.

Kim, E., Duffy, M. and Thorson, E. (2021), “Under the Influence: Social media influencers’ impact on response to corporate reputation advertising”, Journal of Advertising, Vol. 50 No. 2, pp. 119-138.

Kline, R.B. (2011), Principles and Practice of Structural Equation Modeling, Guilford Press, New York, NY.

Knapp, M.L., Vangelisti, A.L. and Caughlin, J.P. (2014), Interpersonal Communication and Human Relationships. Pearson Higher Ed, Boston, MA.

Knoll, J. and Matthes, J. (2017), “The effectiveness of celebrity endorsements: a metaanalysis” Journal of the Academy of Marketing Science, 45(1), 55-75.

Krumpal, I. (2013), "Determinants of social desirability bias in sensitive surveys: a literature review”, Quality \& Quantity, Vol. 47 No. 4, pp. 2025-2047.

Kock, N. (2015), “Common method bias in PLS-SEM: A full collinearity assessment approach”, International Journal of e-Collaboration, Vol. 11 No. 4, pp. 1-10.

Labrecque, L.I. (2014), “Fostering consumer-brand relationships in social media environments: The role of parasocial interaction”, Journal of Interactive Marketing, Vol. 28 No. 2, pp. 134148.

Leite, F.P. and Baptista, P.D.P. (2021), “The effects of social media influencers’ self-disclosure on behavioral intentions: The role of source credibility, parasocial relationships, and brand trust”, Journal of Marketing Theory and Practice.10.1080/10696679.2021.1935275

Leong, L.Y., Hew, T.S., Ooi, K.B. and Wei, J. (2020), “Predicting mobile wallet resistance: A two-staged structural equation modeling-artificial neural network approach”, International Journal of Information Management, Vol. 51, pp. 102047.

Liang, H., Saraf, N., Hu, Q., \& Xue, Y. (2007), “Assimilation of enterprise systems: the effect of institutional pressures and the mediating role of top management”, MIS quarterly, Vol. 31 No. 1, pp. 59-87. 
Lin, R. and Utz, S. (2017), "Self-disclosure on SNS: Do disclosure intimacy and narrativity influence interpersonal closeness and social attraction?”, Computers in Human Behavior, Vol. 70, pp. 426-436.

Liu, C., Zhang, Y., \& Zhang, J. (2020), “The impact of self-congruity and virtual interactivity on online celebrity brand equity and fans' purchase intention”, Journal of Product \& Brand Management, Vol. 29 No. 6, pp. 783-801.

Liu, Y., Mezei, J., Kostakos, V. and Li, H. (2017), “Applying configurational analysis to IS behavioural research: a methodological alternative for modelling combinatorial complexities”, Information Systems Journal, Vol. 27 No. 1, pp. 59-89.

Lo, S.K. (2008), “The impact of online game character's outward attractiveness and social status on interpersonal attraction”, Computers in Human Behavior, Vol. 24 No. 5, pp. 19471958.

Lou, C. (2021), "Social media influencers and followers: Theorization of a trans-parasocial relation and explication of its implications for influencer advertising”, Journal of Advertising. $\underline{10.1080 / 00913367.2021 .1880345}$

Lou, C. and Yuan, S. (2019), “Influencer marketing: how message value and credibility affect consumer trust of branded content on social media”, Journal of Interactive Advertising, Vol. 19 No. 1, pp. 58-73.

Mangus, S.M., Bock, D.E., Jones, E. and Folse, J.A.G. (2020), "Examining the effects of mutual information sharing and relationship empathy: A social penetration theory perspective”, Journal of Business Research, Vol. 109, pp. 375-384.

Martínez-López, F.J., Anaya-Sánchez, R., Esteban-Millat, I., Torrez-Meruvia, H., D’Alessandro, S. and Miles, M. (2020), “Influencer marketing: Brand control, commercial orientation and post credibility”, Journal of Marketing Management, Vol. 36 No. 17-18, pp. 1805-1831.

McCracken, G. (1989), "Who is the celebrity endorser? Cultural foundations of the endorsement process”, Journal of Consumer Research, Vol. 16 No. 3, pp. 310-321.

McQuarrie, E.F., Miller, J. and Phillips, B.J. (2013), “The megaphone effect: taste and audience in fashion blogging. Journal of Consumer Research, Vol. 40 No. 1, pp. 136-158. 
Mehrabian, A. and Russell, J. (1974), An Approach to Environmental Psychology, The MIT Press, Cambridge, MA.

Moraes, M., Gountas, J., Gountas, S. and Sharma, P. (2019), “Celebrity influences on consumer decision making: New insights and research directions”, Journal of Marketing Management, Vol. 35 No. 13-14, pp. 1159-1192.

Muntinga, D.G., Moorman, M. and Smit, E.G. (2011), "Introducing COBRAs: Exploring motivations for brand-related social media use”, International Journal of Advertising, Vol. 30 No. 1, pp. 13-46.

Nitzl, C., Roldan, J.L. and Cepeda, G. (2016), "Mediation analysis in partial least squares path modeling: Helping researchers discuss more sophisticated models”, Industrial Management \& Data Systems, Vol. 116 No. 9, pp. 1849-1864.

Nouri, M. (2018), “The power of influence: traditional celebrity vs social media influencer”, Advanced Writing: Pop Culture Intersections, Vol. 32, available at: https://scholarcommons.scu.edu/engl_176/32.

Ohanian, R. (1990), “Construction and validation of a scale to measure celebrity endorsers' perceived expertise, trustworthiness, and attractiveness”, Journal of Advertising, Vol. 19 No. 3, pp. 39-52.

Pappas, I.O. and Woodside, A.G. (2021), "Fuzzy-set Qualitative Comparative Analysis (fsQCA): Guidelines for research practice in information systems and marketing”, International Journal of Information Management, Vol. 58, pp. 102310.

Park, Y., Fiss, P.C. and El Sawy, O.A. (2020), "Theorizing the multiplicity of digital phenomena: The ecology of configurations, causal recipes, and guidelines for applying QCA”, MIS Quarterly, Vol. 44 No. 4, pp. 1493-1520.

Perse, E.M. and Rubin, R.B. (1989), “Attribution in social and parasocial relationships”, Communication Research, Vol. 16, pp. 59-77.

Podsakoff, P.M., MacKenzie, S.B., Lee, J.Y. and Podsakoff, N.P. (2003), “Common method biases in behavioral research: A critical review of the literature and recommended remedies”, Journal of Applied Psychology, Vol. 88 No. 5, pp. 879-903.

Ragin, C.C. (2008), Redesigning Social Inquiry: Fuzzy Sets and Beyond, University of Chicago Press, Chicago, IL. 
Rasoolimanesh, S.M., Ringle, C.M., Sarstedt, M. and Olya, H. (2021), “The combined use of symmetric and asymmetric approaches: partial least squares-structural equation modeling and fuzzy-set qualitative comparative analysis”, International Journal of Contemporary Hospitality Management, Vol. 33 No. 5, pp. 1571-1592.

Raven, B.H. (1965), “Social influence and power”, in Steiner, I. D. and Fishbein, M. (Eds), Current Studies in Social Psychology, Holt, Rinehart \& Winston, New York, NY, pp. 371-382. Reinikainen, H., Munnukka, J., Maity, D. and Luoma-aho, V. (2020), "You really are a great big sister"- parasocial relationships, credibility, and the moderating role of audience comments in influencer marketing”, Journal of Marketing Management, Vol. 36 No. 3-4, pp. 279-298.

Rosenthal, B. and Brito, E.P. (2017), "How virtual brand community traces may increase fan engagement in brand pages”, Business Horizons, Vol. 60 No. 3, pp. 375-384.

Sakib, M.N., Zolfagharian, M. and Yazdanparast, A. (2020), "Does parasocial interaction with weight loss vloggers affect compliance? The role of vlogger characteristics, consumer readiness, and health consciousness”, Journal of Retailing and Consumer Services, Vol. 52, pp. 101733.

Schimmelpfennig, C. and Hunt, J.B. (2020), "Fifty years of celebrity endorser research: Support for a comprehensive celebrity endorsement strategy framework”, Psychology \& Marketing, Vol. 37 No. 3, pp. 488-505.

Schneider, C.Q. and Wagemann, C. (2010), "Standards of good practice in qualitative comparative analysis (QCA) and fuzzy-sets”, Comparative Sociology, Vol. 9 No. 3, pp. 397418.

Shan, Y., Chen, K.J. and Lin, J.S. (2020), "When social media influencers endorse brands: the effects of self-influencer congruence, parasocial identification, and perceived endorser motive”, International Journal of Advertising, Vol. 39 No. 5, pp. 590-610.

Shen, Y.C., Huang, C.Y., Chu, C.H. and Liao, H.C. (2010), “Virtual community loyalty: an interpersonal-interaction perspective”, International Journal of Electronic Commerce, Vol. 15 No. 1, pp. 49-74.

Sokolova, K. and Kefi, H. (2020), “Instagram and YouTube bloggers promote it, why should I buy? How credibility and parasocial interaction influence purchase intentions”, Journal of Retailing and Consumer Services, Vol. 53, pp. 101742. 
Sprecher, S., Treger, S., Wondra, J.D., Hilaire, N. and Wallpe, K. (2013), “Taking turns: reciprocal self-disclosure promotes liking in initial interactions”, Journal of Experimental Social Psychology, Vol. 49 No. 5, pp. 860-866.

Swani, K., Milne, G.R., Brown, B.P., Assaf, A.G. and Donthu, N. (2017), "What messages to post? Evaluating the popularity of social media communications in business versus consumer markets”, Industrial Marketing Management, Vol. 62, pp. 77-87.

Tafesse, W. and Wood, B.P. (2021), “Followers' engagement with instagram influencers: The role of influencers' content and engagement strategy”, Journal of Retailing and Consumer Services, Vol. 58, pp. 102303.

Tan, G.W.H. and Ooi, K.B. (2018), “Gender and age: Do they really moderate mobile tourism shopping behavior?”, Telematics and Informatics, Vol. 35 No. 6, pp. 1617-1642.

Tan, G.W.H., Lee, V.H., Hew, J.J., Ooi, K.B. and Wong, L.W. (2018), “The interactive mobile social media advertising: an imminent approach to advertise tourism products and services?”, Telematics and Informatics, Vol. 35 No. 8, pp. 2270-2288.

Thomson, M. (2006). Human brands: investigating antecedents to consumers' strong attachments to celebrities. Journal of Marketing, Vol. 70 No. 3, pp. 104-119.

Till, B.D. and Busler, M. (2000), “The match-up hypothesis: physical attractiveness, expertise, and the role of fit on brand attitude, purchase intent and brand beliefs”, Journal of Advertising, Vol. 29 No. 3, pp. 1-13.

Torres, P., Augusto, M. and Matos, M. (2019), “Antecedents and outcomes of digital influencer endorsement: an exploratory study”, Psychology \& Marketing, Vol. 36 No. 12, 1267-1276.

Tukachinsky, R. and Stever, G. (2019), “Theorizing development of parasocial engagement”, Communication Theory, Vol. 29 No. 3, pp. 297-318.

Tukachinsky, R., Walter, N. and Saucier, C.J. (2020), “Antecedents and effects of parasocial relationships: a meta-analysis. Journal of Communication, Vol. 70 No. 6, pp. 868-894.

Tuškej, U. and Podnar, K. (2018), “Consumers’ identification with corporate brands: Brand prestige, anthropomorphism and engagement in social media”, Journal of Product \& Brand Management, Vol. 27 No. 1, pp. 3-17. 
Wang, P., Huang, Q., \& Davison, R. M. (2020). How do digital influencers affect social commerce intention? The roles of social power and satisfaction. Information Technology \& People, Vol. 34 No. 3, pp. 1065-1086.

Wheeless, L.R. and Grotz, J. (1977), “The measurement of trust and its relationship to selfdisclosure”, Human Communication Research, Vol. 3 No. 3, pp. 250-257.

Xiang, L., Zheng, X., Lee, M.K.O. and Zhao, D. (2016), “Exploring consumers’ impulse buying behavior on social commerce platform: The role of parasocial interaction”, International Journal of Information Management, Vol. 36 No. 3, pp. 333-347.

Yuan, C., Moon, H., Wang, S., Yu, X. and Kim, K.H. (2021), "Study on the influencing of B2B parasocial relationship on repeat purchase intention in the online purchasing environment: an empirical study of B2B E-commerce platform”, Industrial Marketing Management, Vol. 92, pp. 101-110.

Yuan, C.L., Kim, J. and Kim, S.J. (2016), "Parasocial relationship effects on customer equity in the social media context”, Journal of Business Research, Vol. 69 No. 9, pp. 3795-3803.

Yuan, C.L., Moon, H., Kim, K.H. and Wang, S. (2019), "The influence of parasocial relationship in fashion web on customer equity”, Journal of Business Research, Vol. 130, pp. 610-617.

Yuan, C.W. and Lee, Y.-H. (2021), “Connecting and being connected: investigating friending practices across multiple social networking sites”, Information Technology \& People, available at: https://doi.org/10.1108/IJCHM-10-2020-1164

Yuan, S. and Lou, C. (2020), “How social media influencers foster relationships with followers: the roles of source credibility and fairness in parasocial relationship and product interest”, Journal of Interactive Advertising, Vol. 20 No. 2, pp. 133-147.

Zhang, H., Liang, X. and Moon, H. (2020), "Fashion cewebrity involvement in new product development: scale development and an empirical study”, Journal of Business Research, Vol. 120, pp. 321-329. 


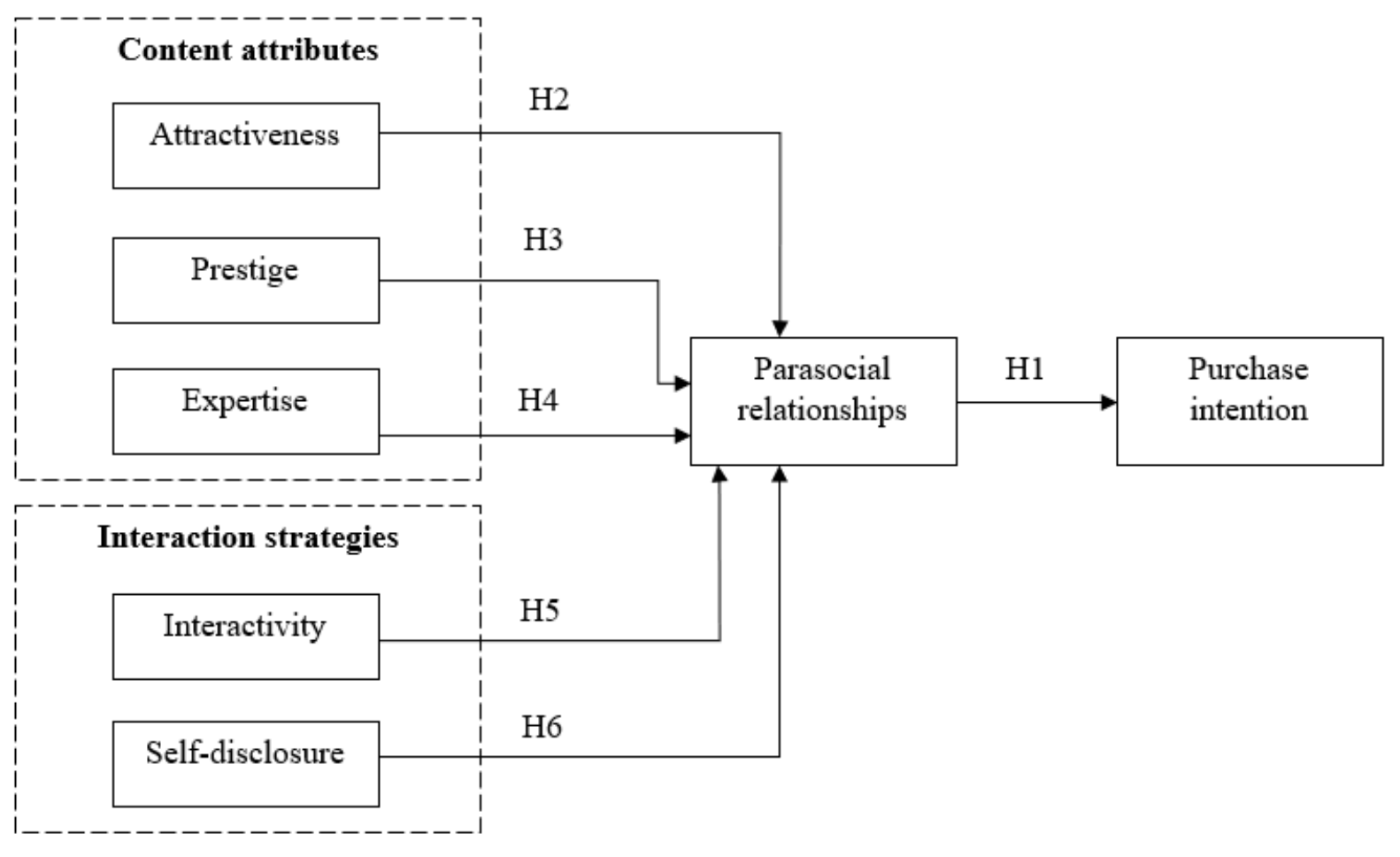

Fig 1. PLS-SEM research model 


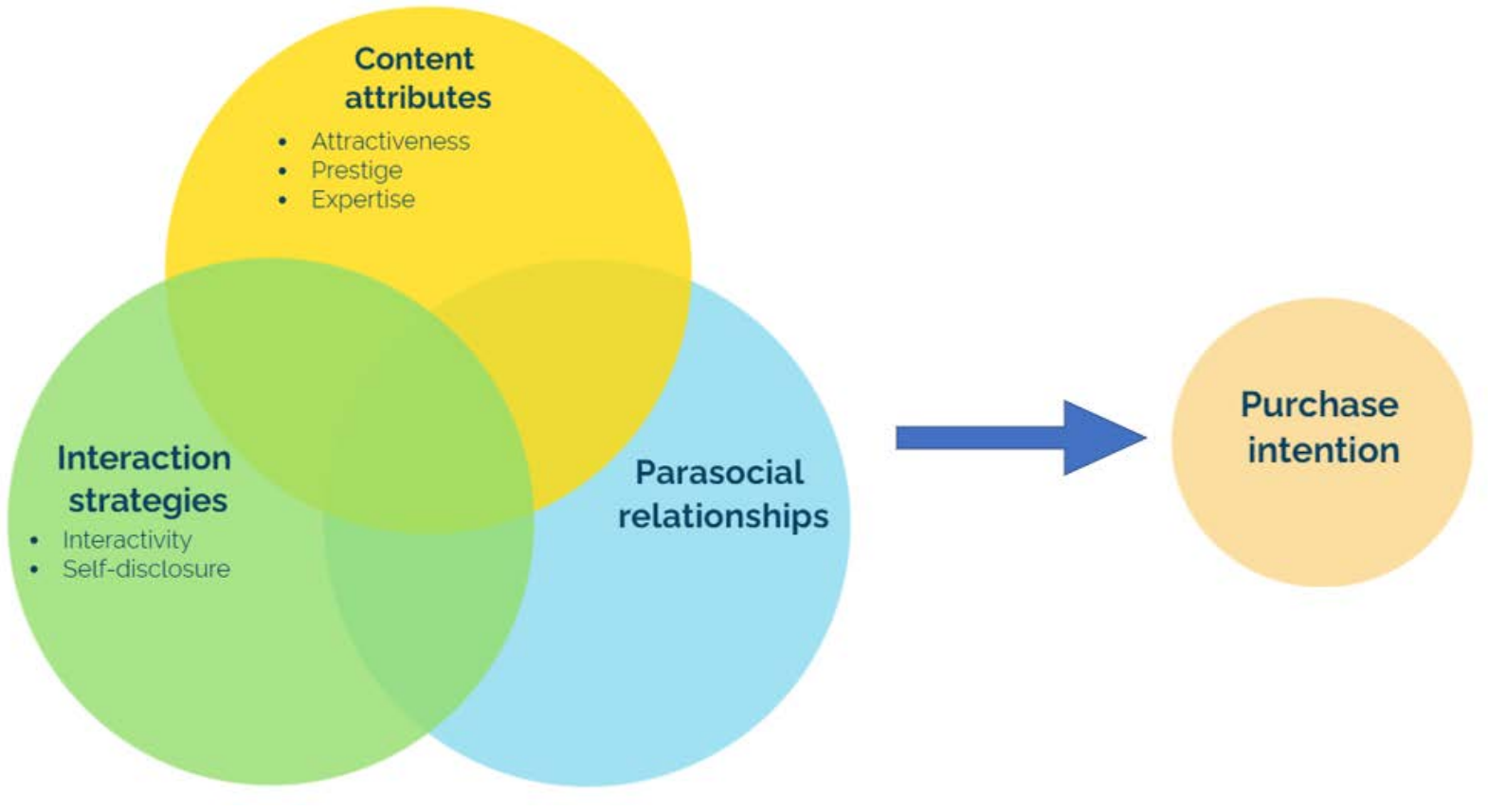

Fig 2. Configurational model 


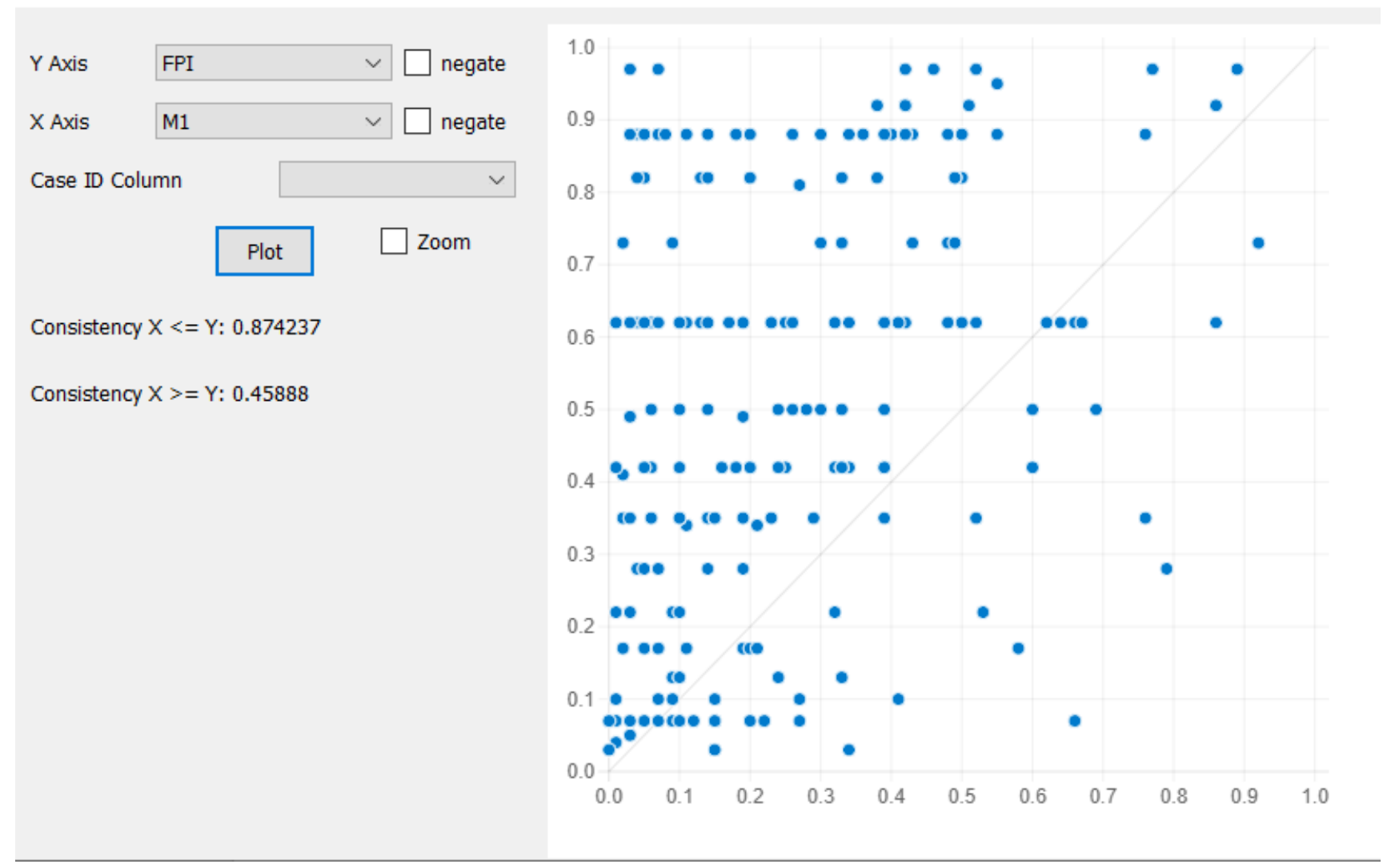

Fig 3. Testing for predictive validity 